\title{
Protetik diş hekimliğinde 3-boyutlu implant planlama ve cerrahi kılavuzlar
}

\author{
Abdullah Oğuz Hamiş, ${ }^{*}$ Oğuz Ozan, \\ Serhat Ramoğlu \\ Protetik Diş Tedavisi Anabilim Dalı, Yakın Doğu Üniversitesi \\ Diş Hekimliği Fakültesi, Lefkoşa, Kuzey Kıbrıs Türk Cumhuriyeti
}

\section{ÖZET}

Günümüzde, geleneksel cerrahi yöntemlerle yapılan implant tedavilerindeki başarısızlıkları azaltmak için teknolojinin sunduğu imkanlardan yararlanılıp daha başarılı tedaviler yapılabilmektir. Bu amaçla yapılan 3-boyutlu planlama neticesinde implant yerleştirilecek bölgedeki kemiğin yoğunluğu, genişliği ve anatomik oluşumlar ayrıntılı gözlemlenebilmekte ve kemik dokunun 3-boyutlu modeli oluşturulabilmektedir. Uygun radyolojik kılavuzlar kullanılarak yapılan planlama ve üretilen cerrahi kılavuzlar sayesinde, protetik olarak daha başarılı implant destekli restorasyonların kullanıma sunulması mümkün olabilmektedir. Bu derlemede, dental implant tedavilerinde başarılı protetik sonuçlar elde etmek için yapılan planlama yöntemleri hakkında bilgi verilmiş ve bu yöntemlerin hassasiyeti güncel literatür eşliğinde değerlendirilmiştir.

Anahtar Kelimeler: Cerrahi, bilgisayar yardımlı; diş implantı; prostodonti

Kaynak Göstermek İçin: Hamiş AO, Ozan O, Ramoğlu S. Protetik diş hekimliğinde 3-boyutlu implant planlama ve cerrahi kılavuzlar. Acta Odontol Turc 2016;33(1):55-62

EрітӧR: Özgül Karacaer, Gazi Üniversitesi, Ankara, Türkiye

YAYıN HAKKı: () 2016 Hamiş ve ark. Bu eserin yayın hakkı Creative Commons Attribution License ile ruhsatlandırılmıştır. Sınırsız kullanım, dağıtım ve her türlü ortamda çoğaltım, yazarlar ve kaynağın belirtilmesi kaydıyla serbesttir.

[Abstract in English is at the end of the manuscript]

\section{Giriş}

Modern diş hekimliğinin en önemli amaçlarını, hastaların fonksiyon, fonasyon ve estetik beklentilerinin sağlanması oluşturmaktadır. ${ }^{1}$ Birçok hasta kullanım kolaylığı başta olmak üzere, doğallığı, psikolojik olarak bütünlük duygusu gibi çeşitli sebeplerden dolayı sabit protetik restorasyonları tercih etmektedir. ${ }^{2}$ Son 40 yıl içerisinde dental im-

Makale gönderiliş tarihi: 22 Ağustos 2014 ; Yayına kabul tarihi: 21 Ocak 2015 *iletişim: Abdullah Oğuz Hamiş, Yakın Doğu Üniversitesi Diş Hekimliği Fakültesi, Protetik Diş Tedavisi Anabilim Dalı, Lefkoşa, Kuzey Kıbrıs Türk Cumhuriyeti; e-posta: oguzhamis@gmail.com plantlar, eksik dişlerin ve oral dokuların desteklenmesinde geleneksel olarak kullanılan hareketli veya sabit protezlere alternatif olmuşlardır. ${ }^{3}$ Teknolojinin de ilerlemesi ile geçtiğimiz son yıllarda diş hekimliğinde implantoloji bilimi ile ilgili gözle görülür birçok bilimsel ilerleme olmuştur. ${ }^{4}$ Bu teknolojik ilerlemeler, dental implant tedavisinin, tam dişsizlik ya da bölümlü dişsizlik vakalarında altın standart olarak gösterilmesini sağlamıştır. ${ }^{5,6}$

Başarılı bir implant destekli protetik tedavide en önemli nokta doğru bir planlamanın yapılmasıdır.7-10 Teknolojinin gelişmesi ile geleneksel cerrahi yöntemlerle yapılan implant tedavilerindeki başarısızlıkların önüne geçilerek başarı oranı yükseltilmeye çalışılmıştır. ${ }^{8,10} \mathrm{Bu}$ amaçla, günümüz diş hekimliğinde uygun radyolojik ve cerrahi kılavuzların kullanıması ile protetik olarak daha başarılı implant destekli restorasyonların kullanıma sunulması mümkün olabilmektedir. Yapılacak olan uygun planlama ile şu avantajlar sağlanabilir: operasyon süresinin kısalması, implant cerrahisinde daha başarılı bir sonuç elde edilmesi, operasyon sırasında beklenmedik hata ve komplikasyonlar ile karşılaşılmaması ve hasta açısından operasyon sonrası daha rahat bir dönem geçirilmesi. ${ }^{11-13}$

$\mathrm{Bu}$ derlemede dental implant tedavilerinde başarıı protetik sonuçlar elde etmek için gerekli planlama yöntemleri hakkında bilgi verilmekte ve bu yöntemlerin hassasiyetleri güncel literatür eşliğinde değerlendirilmektedir.

\section{Dental implantolojide tedavi planlaması}

Başarılı bir implant tedavisinde en önemli etken, klinik ve radyolojik olarak yapılan muayenedir..$^{13}$ Tedavi planlaması ve cerrahi işlem öncesi hasta değerlendirilirken, cerrahi işlemi ve protetik işlemi gerçekleştirecek olan hekimlerin beraber kemik miktarı ve protezin istenilen nihai konumunu göz önünde bulundurarak implantın en uygun konumunu belirlemesi önem kazanmaktadır. ${ }^{13-15}$ Yanlış planlanmış bir olgu, hekim ve hasta için istenmeyen sonuçlar doğuracaktır. ${ }^{14-17}$

İmplant tedavilerinde en önemli noktalardan biri mevcut olabilecek olan risk faktörlerinin göz önünde bulundurulmasıdır. ${ }^{13-18}$ Genel olarak bu risk faktörleri; hastanın yaşı, cinsiyeti, sistemik sağlık durumu (diyabet, hipertansiyon, kardiyovasküler hastalıklar, vs), sigara ve alkol kullanım du- 
rumu, implantın özellikleri; sayısı, boyutları, hangi çeneye yapıldığı, çenelerde hangi bölgeye yapıldığı (ön-arka bölge, hangi diş yerine yapıldığı vb.) ve implant yapılan bölgede diş kaybetme nedenleri olarak ifade edilmektedir. ${ }^{13-18} \mathrm{Mev}-$ cut risk faktörlerinin azaltılması konusunda implant planlamasının önemi üzerinde durulmaktadır. ${ }^{13-19}$

Literatürde, başarılı bir tedavi planlaması için, klinik ve radyolojik muayene ile çalışma modellerinin öneminden söz edilmektedir. ${ }^{13-16}$

\section{Klinik muayene}

Klinik muayenenin en önemli ve ilk aşaması dişsel ve tıbbi anamnezdir. İntra-oral olarak yapılan incelemede oral hijyenin, yumuşak dokuların, dişli ve dişsiz boşlukların durumu değerlendirilip, dişler ve oklüzyon detaylıca incelenmelidir. Alt ve üst çenenin birbiri ile ilişkisi de dikkatle değerlendirilir. ${ }^{1,13,16}$

\section{Çalışma modelleri}

Cerrahi operasyon öncesi çalışma modelleri elde edilerek çenelerin 3-boyutlu kopyaları değerlendirilir. Ağız içi fotoğraflar aracılığı ile hasta ağzının detaylı incelenmesi sağlanır. 1,13,16

\section{Radyolojik muayene}

Radyolojik görüntüleme hem hasta için hem de hekim için kapsamlı bir tedavi planı oluşturulması açısından en önemli aşamalardan biridir. ${ }^{20-23}$ Radyolojik inceleme, mevcut kemik kalite ve kantitesinin belirlenmesi ile uygulanacak olan implantın boyu, çapı ve anatomik yapılarla olan ilişkisinin değerlendirilmesine yardımcı olur. 6,18,19,21 Dental implant planlamasında başarıya ulaşmak için kullanılan çeşitli radyolojik yöntemler ve bu yöntemlerin kullanım sınırları Tablo 1'de gösterilmiştir.

\section{Bilgisayar destekli implant planlaması}

Geleneksel dental implant tedavisinde planlama, cerrahi operasyon ve protetik restorasyon sırası ile giden tedavi basamaklarından meydana gelmektedir. Üç-boyutlu planlamada ise bu basamaklar, simüle edilmiş protetik resto- rasyon, bu protetik restorasyona göre yapılan planlama ve cerrahi operasyon şeklindedir. Böylelikle implantların konumu, paralellikleri, boyutları ve sayısının hastanın bitmiş protezi üzerinden planlanması sağlanmaktadır. Bu yöntem kullanılarak, karşılaşılabilecek olan sorunların operasyon öncesi fark edilmesi sağlanmış olunur.8,12,13,22

Üç-boyutlu tedavi planı ile, implant uygulanması düşünülen bölgenin kemik genişliğinin miktarını, optimal uzunluğunu ve derinliğini, kortikal kemiğin varlığını ve miktarını, trabeküler kemiğin mineralizasyon derecesini ve anatomik oluşumları belirleyerek, implantların paralelliğini ayarlamak mümkündür. Bu teknikler nicel olarak kesindir ve geliştirilen programlar ile; hastanın 3-boyutlu modelleri oluşturulabilir, ağıza net olarak uyan cerrahi plaklar ve protetik restorasyonlar üretilebilir. ${ }^{23-25}$ Günümüzde en sık kullanılan 3-boyutlu implant planlama programlarına örnek olarak şunlar verilebilir: Nobel Clinician (Nobel Biocare AG, İsviçre), StentCad Ötede (AyTasarım Ltd. Şti., Türkiye), Implant 3D (MediaLab, İtalya), Simplant (Dentsply Implant, ABD), Implant Logics (Hi-Tec Implant, İsrail). Resim 1'de bu programlardan birine ait arayüz görülmektedir.

Üç-boyutlu implant planlamasının en önemli basamaklarından biri, radyoloji safhasında kullanılacak olan radyolojik kılavuzlardır. 2,8,13,19,26,27 Bu kılavuzların en önemli özellikleri, içerilerine katılan baryum sülfat kristalleri, gütta-perka topları ya da şeritleri, metal pinler ya da tüpler, radyoopak vernikler veya kuşun folyolar sayesinde belirli bir radyoopasiteye sahip olmalarından yararlanılarak çeşitli rehber yapılar elde edilmesidir (Resim 2). Radyolojik kılavuz sayesinde sonuç proteze göre implant planlamasının yanı sıra yumuşak dokunun kalınlığı hakkında da bilgi sahibi olunabilir. ${ }^{14,23-28}$ (Resim 3). Radyolojik kılavuz ile implantların nihai konumu bilgisayarda simüle edilmiş olunur.

Üç-boyutlu implant planlama programları ile planlanmış olan implantların konumları cerrahi bölgesine rehber plaklarla aktarılır. Bu amaçla geleneksel cerrahi rehber plaklar veya stereolitografik rehber plaklar kullanılabilmektedir. Rehber plaklar hekime doğru tanı ve

Tablo 1. Radyolojik yöntemler ve özellikleri

\begin{tabular}{llll}
\hline Yöntem & Endikasyonları & Avantajları & Sınırları \\
\hline Periapikal radyografi & 1 diş eksikliği & İyi çözünürlük, detay bilgisi verir & $\begin{array}{c}\text { Küçük inceleme alanı, 2-boyutlu olması, } \\
\text { magnifikasyon }\end{array}$ \\
Panoramik radyografi & $\geq 1$ diş eksikliği & Anatomik yapılar ve birbirleri ile ilişkileri incelenebilir & Düşük çözünürlük, magnifikasyon \\
Bilgisayarı tomografi (BT) & $\geq 1$ diş eksikliği & Kemik ile ilgili tüm ölçümler yapılabilir & Yüksek maliyet \\
Konik ışınlı bilgisayarlı tomografi (KIBT) & $\geq 1$ diş eksikliği & $\begin{array}{c}\text { Kemik ile ilgili tüm ölçümler yapılabilir ve } \\
\text { düşük radyasyon dozuna sahiptir }\end{array}$ & Yüksek maliyet \\
Interaktif BT & $\geq 1$ diş eksikliği & $\begin{array}{c}\text { Kemik ile ilgili tüm ölçümler yapıllabilir, } \\
\text { düşük radyasyon dozuna sahiptir, 3-boyutlu bilgisayar } \\
\text { programlarında implantlar planlanabilir }\end{array}$ & \\
& & Yüksek maliyet \\
\hline
\end{tabular}




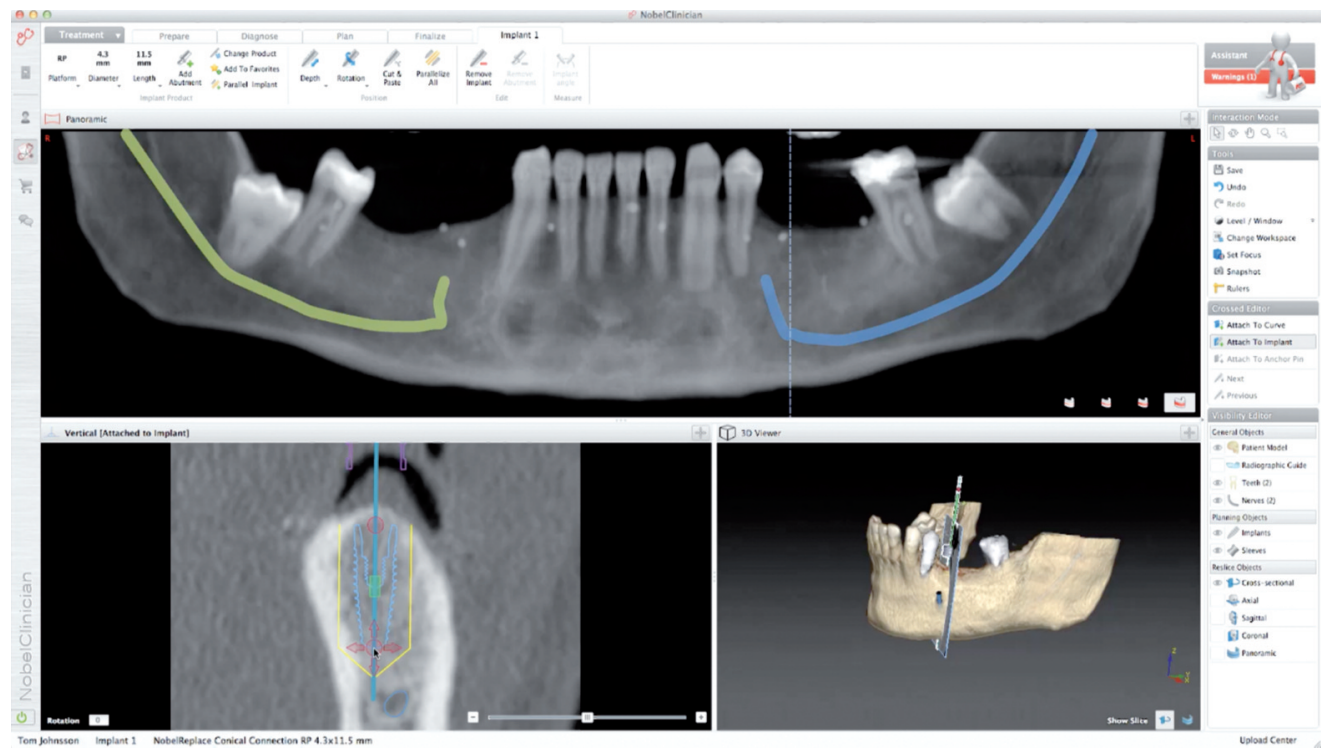

Resim 1. Implant planlama programının arayüzü

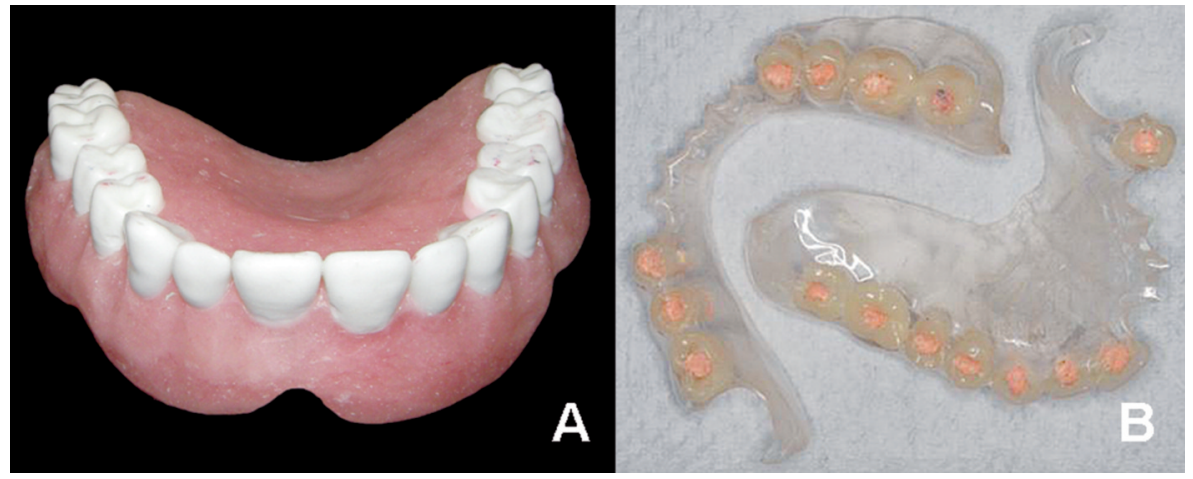

Resim 2. İki farklı tipte radyolojik kılavuz; A: Baryum sülfat kristalleri içeren radyolojik kılavuz, B: Gütta-perka şeritleri içeren radyolojik kılavuz

doğru tedavi planlamasının yapılmasında yardımcı olurken; dental implantların kemik içinde doğru konumda ve doğru açıda yerleştirilmelerini de sağlar. ${ }^{26-29}$ Uygun bir şekilde planlanmış rehber plak ile implantların yerleştirilmesinin klinik ve laboratuvar komplikasyon riskini de azaltacağı bildirilmiştir. ${ }^{9,28}$

Güncel gelişmeler ışığında cerrahi rehber kılavuzları 3 ayrı grupta incelemek mümkündür.

- Geleneksel cerrahi kılavuzlar ${ }^{1}$

- CAD/CAM cerrahi kılavuzlar (Stereolitografik cerrahi kılavuzlar) $)^{8,10,11,20,26}$

- Navigasyon yöntemi ile uygulanan cerrahi kılavuzlar. ${ }^{30}$

\section{Geleneksel cerrahi kılavuzlar}

Geleneksel cerrahi kılavuzlar, planlanan implantların açılarını cerrahiye aktarmaktan çok, yerleştirilecek olan bölgenin tespitini mümkün kılmaktadır. ${ }^{31-35} \mathrm{Bu}$ şekilde, implantların eksik olan dişlerin boyutlarına göre birbirlerine olan uzaklıkları ve konumları istenilen şekilde ayarla- nabilmektedir. ${ }^{36} \mathrm{Bu}$ yer belirleme işlemi, bitmiş protezlere açılan deliklerle olabileceği gibi bu protezlerin üzerine sert splint koyularak da elde edilebilir (Resim 4). ${ }^{32-36}$

\section{CAD/CAM cerrahi kılavuzlar}

\section{(stereolitografik cerrahi kılavuzlar, SLA kılavuzlar)}

Son yıllarda radyolojik ve cerrahi kılavuzların kullanımı ile dental implant rehabilitasyonunda protetik ve estetik alanlarda başarılı sonuçlar elde edildiğine literatürde yer verilmektedir.9,13,19,37-39 Yapılması düşünülen protetik restorasyona uyumlu olarak hazırlanan radyolojik kılavuzların kullanılmasıyla implant desteklerin estetik ve fonksiyonel anlamda en uygun konumda yerleştirilmesi mümkün olmaktadır. ${ }^{40}$ Buna rağmen bu bilgilerin cerrahi faza aktarılması hala büyük zorluklar taşımaktadır. ${ }^{41} \mathrm{Mev}$ cut bu zorlukların giderilmesinde CAD/CAM sistemleri ile kombine olarak kullanılan konik ışınlı bilgisayarlı tomografi/bilgisayarlı tomografi (KIBT/BT) tekniği günümüzde sıklıkla kullanılmaktadır. ${ }^{19,25,27,42,43}$ Bu tekniklerden biri olan stereolitografi (SLA) yöntemi kullanılarak lazer polimeri- 


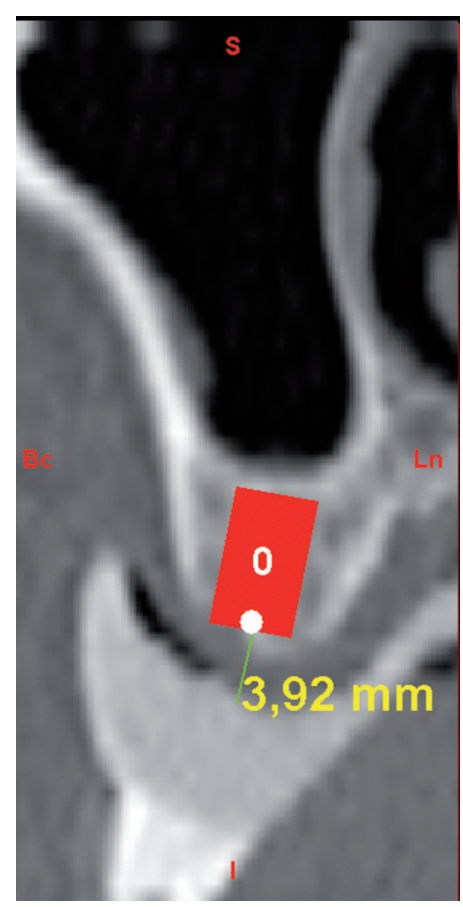

Resim 3. Radyolojik kılavuz sayesinde yumuşak doku kalınlığı hakkında ölçüm yapılabilir.

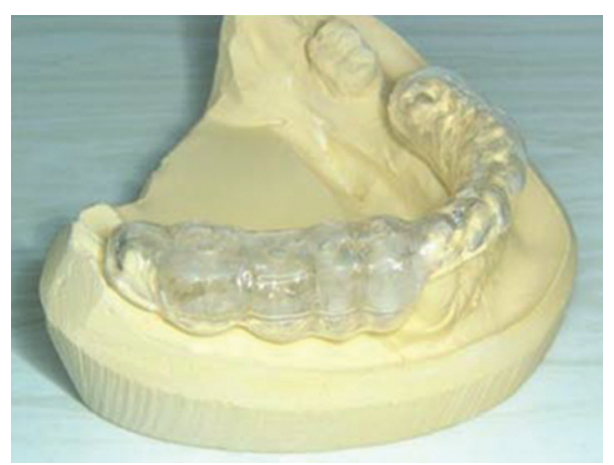

Resim 4. Isı ile şekillenebilen geleneksel cerrahi rehber

zasyon işlemi ile anatomik modelden cerrahi kılavuz elde edilebilmektedir. ${ }^{13,19,20,27}$ Stereolitografi, lazer ışını kullanılarak ultraviole ışına hassas, sıvı rezinin seçici olarak sertleşerek model elde etme işlemidir. ${ }^{28}$ Bu sistemde; fotopolimer reçine üzerinde parçanın kesiti lazer ile taranarak reçinenin sertleştirilmesi sağlanır. Dikey ekseninde tabla bir kat kalınlığında aşağı yönde hareket eder ve lazer tekrar parçanın o kesiti doğrultusunda reçineyi sertleştirir. Bu işlem üretilecek modelin dikey yüksekliği kadar devam eder; bittikten sonra parça yüzeyindeki artık reçineler kimyasallar ile temizlenir. ${ }^{10,13,19,22}$. Bu sistem sayesinde cerrahi kılavuz üretilebildiği gibi, çene kemiğinin yüksek kalitede modellenmesi sağlanır. ${ }^{25}$

Stereolitografik kılavuzlarla operasyon flepsiz olarak gerçekleştirilebilir, ${ }^{20}$ bu şekilde operasyon süresi kısalıp post-operatif ödem, kanama, ve ağrı kesici kullanımının en aza indirgenmesi sağlanılır. ${ }^{26,27}$ Stereolitografik cer- rahi kılavuzların kullanımında yukarıda söz edilen avantajlarının yanı sıra, hekim sistemin tüm detayları ve KIBT/BT hakkında bilgi sahibi olması gerekliliği ön plana çıkmaktadır. ${ }^{30-32}$ Aksi halde bazı komplikasyonlar ve uygulamada güçlüklerle karşılaşılabilir. ${ }^{13,21,26,36}$

SLA cerrahi kılavuzların implant cerrahisinde kullanımı avantajı görünmesine karşın her implant operasyonunda kullanılması gerekliliği düşünülmemelidir. Bu gibi yöntemlerde, tedavinin planlama süresinin uzaması, ekstra radyasyona maruz kalınması, maliyetinin yüksek olması gibi nedenlerle, fayda ve zarar dikkatlice değerlendirilmeli ve belli endikasyonlar belirlenmelidir. Yapılan literatür taramasında genel olarak şu durumlarda stereolitografik cerrahi rehber kılavuzların kullanımının uygun olacağı belirtilmektedir: ${ }^{13,23,37-43}$

- Yan yana 3 veya daha fazla implant yerleştirilmesi planlanan vakalarda

- Anatomik yapılarla çok yakın komşuluk bulunduğu durumlarda (maksiller sinüs veya alveolar kanala bulunan yakın komşuluklar, vb)

- Yetersiz kemik desteğinin bulunduğu vakalarda

- Planlanan restorasyona göre implant konumunun kritik olduğu durumlarda

- Flepsiz implant yerleştirilmesi düşünülen vakalarda

- Immediat implant uygulamalarında

- Fiziksel, medikal veya psikolojik problemli hastalarda

- Hastanın operasyon sonrası rahatının düşünüldüğü durumlarda

Bu cerrahi kılavuz sistemi ile bilgisayarda tasarlanan tedavi planı; cerrahi operasyona minimum hata payı ve maksimum adaptasyonla aktarılmaktadır. ${ }^{44} \mathrm{Bu}$ tarz kılavuzlar, frez yönlendirici veya anguldruva yönlendirici olarak hazırlanmaktadırlar. ${ }^{8,10,19,45}$

\section{Frez yönlendirici kılavuzlar}

Frez yönlendirici kılavuzlar bukkolingual ve mesiodistal düzlemlerde, osteotomide kullanılan bütün aletleri açısal ve konumsal olarak kısıtlarlar. ${ }^{9,13,26,36}$ Cerrahi kılavuz üretilirken implantın yerleşeceği bölgeler planlama aşamasında belirlenir ve ilk frezin geçeceği paslanmaz çelik tüp yerleştirilir. Bu tarz kılavuzların 2 çeşidi vardır. Birincisinde hekimin tercihine göre her frez için farklı çapta tüpleri olan rehber kılavuzlar hazırlanır (Resim 5). Operasyon sırasında hekim her yeni frez aşamasında rehberi değiştirir. ${ }^{13,46}$ Diğer sistemde ise tek rehber kullanılır fakat her çap frez için bir adaptör parça yardımıyla paslanmaz çelik frez kanallarının çapı değiştirilir (Resim 6) ${ }^{47}$

Birden fazla rehber kullanımının bazı dezavantajları da bulunmaktadır. Hazırlanan stereolitografik plakların içerisinde bulunan paslanmaz çelik materyaline frezin temas etmesi sonucu çıkan partiküller alvoler kemiğe inokule olabilir. ${ }^{20}$ Ayrıca, implant yuvası hazırlanırken yeterli irrigas- 


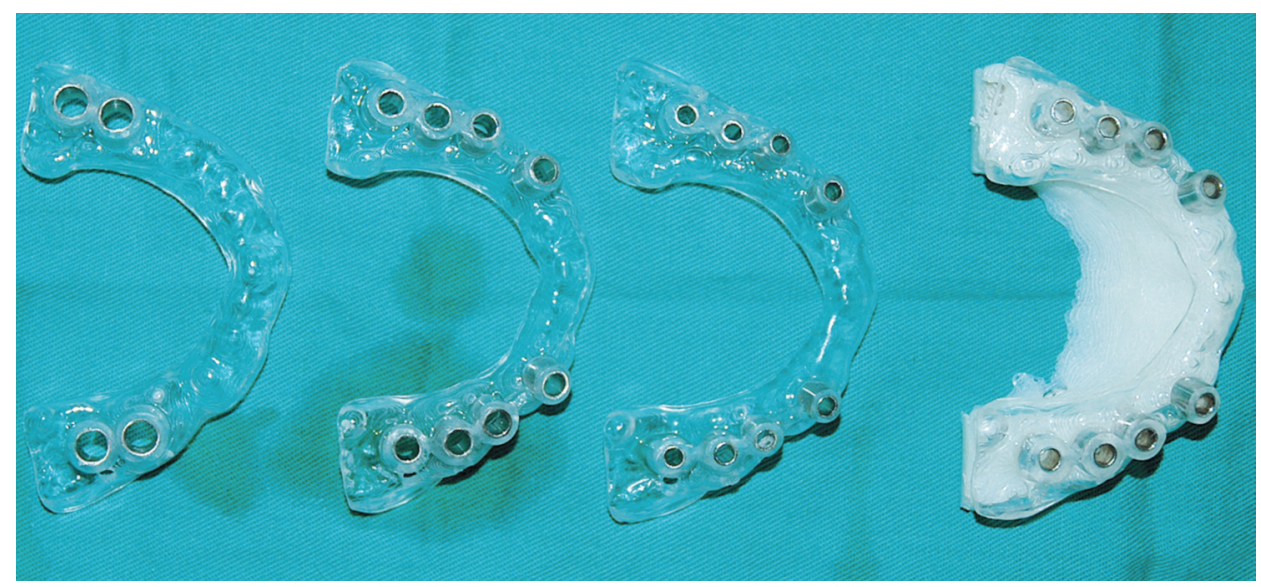

Resim 5. Farklı çapta tüpleri olan frez yönlendirmeli rehber kılavuzlar

yonun sağlanamamasından dolayı rehbersiz yönteme göre kemiğin daha fazla ısınmasına sebep olunabilir. ${ }^{47,48}$ Bunun yanında, total dişsiz vakalarında, kılavuzların ağız içerisinde sabitlenme problemleriyle karşılaşılabileceği için yerleştirilen implantlarda açısal sapmalar olabilir. ${ }^{13,26}$

\section{Anguldruva yönlendirici kılavuzlar}

Cerrahi frezleri yönlendiren klasik sistemlerin aksine anguldruvayı yönlendirmekte olan bu sistem 2 parçadan oluşmaktadır. ${ }^{33}$ Bu parçalardan ilki hastanın çene kemiğine yerleştirilen cerrahi kılavuzdur. Diğer parça ise ağız içerisindeki cerrahi kılavuzda bulunan yönlendirici pinlerle uyumlu "anguldruva yönlendirici" parçadır (Resim 7). Bu uyum ile, hem frezin kemik doku içerisindeki derinlik kontrolü hem de pinin sağladığı sabitleme ile implant açısının programda planlandığı gibi olması sağlanabilmektedir. ${ }^{19,36}$ Kullanılan bu kılavuz sistemi ile implantların yerleştirilmesindeki hassasiyet ve böylelikle paralelliğin artabileceği düşünülmektedir. ${ }^{37}$

Anguldruva yönlendirici kılavuzlar sayesinde, anguldruva başlığının pozisyonu sabitlenmektedir. Böylece frezlerin teması sonucu frez rehberlerinde görülen ısınma ve tüplere temas sonucu oluşan çapaklanma oluşmamaktadır. Aynı zamanda her bir cerrahi frez için farklı cerrahi kılavuz adaptasyonu gerekmemektedir. . $^{1326,36}$

Ayrıca bu tüplerin uzunluğu planlanan implantın boyuna göre ayarlanmaktadır. Pinlerin tüp içerisine tam olarak yerleştirilmesi anguldruvanın maksimum ilerleyebileceği derinliğin kontrolünü sağlamaktadır. Bu tarz kılavuzlarla anguldruvaya takılabilen her parça yönlendirilebilir. Böylelikle implantlar da kemik içerisine anguldruva yardımı ile yerleştirilebilir. Kılavuzun ağız içinde stabilitesini sağlamak için osseosentez vidalar kullanılabilir (Resim 8). ${ }^{45-49}$

\section{Destek aldığı dokulara göre cerrahi kılavuzlar}

Cerrahi kılavuzlar, uygulanma yöntemleri haricinde destek alınan dokulara göre de; diş, kemik ve mukoza destekli

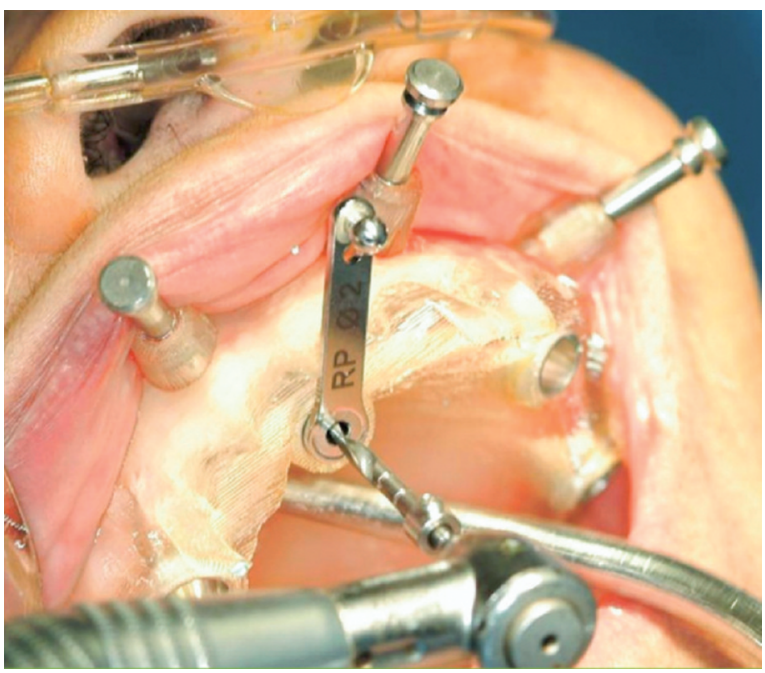

Resim 6. Tek rehber kullanılarak ve her çap frez için bir adaptör parça yardımıyla frez kanallarının çapı değiştirilen frez yönlendirmeli rehber kılavuz

olarak da sınıflandırılır. 13,26,36,50,51 Diş destekli SLA cerrahi kılavuzlar kısmi dişsiz çenelerde kullanılmaktadır. Plak dişler üzerine sabitlenir ve hareketleri kısıtlanmış olur. Mukoza destekli SLA cerrahi kılavuzlar genellikle tam dişsiz çenelerde kullanılır ve mukoza üzerine yerleştirilir. Plağı sabitlemek ve hareket etmesini önlemek için stabilizasyon pinleri kullanılır. ${ }^{25}$ Cerrahi kılavuzların uygun konumda ağızda sabitlenmesi için doğru alınmış kapanış kaydının bulunması gerekmektedir..$^{13,26,36}$ Kemik destekli cerrahi kılavuzlar tam ya da kısmi dişsiz çenelerde kullanılabilir fakat genellikle atrofik çene kemiğine sahip, mukoza konumunun şüpheli olduğu veya augmentasyon ihtiyacı olan vakalarda kullanılabilmektedir. ${ }^{45} \mathrm{Bu}$ tür cerrahi kılavuzlar kemik üzerinde doğru olarak konumlandırmak için flebin geniş kaldırılması gerekmektedir. ${ }^{43,45,52}$

\section{Navigasyon yöntemi ile hazırlanan kılavuzlar}

Navigasyon yöntemi ile hazırlanan kılavuzlar dental implantolojinin in vivo olarak çalışılan yeni kılavuz sistemle- 


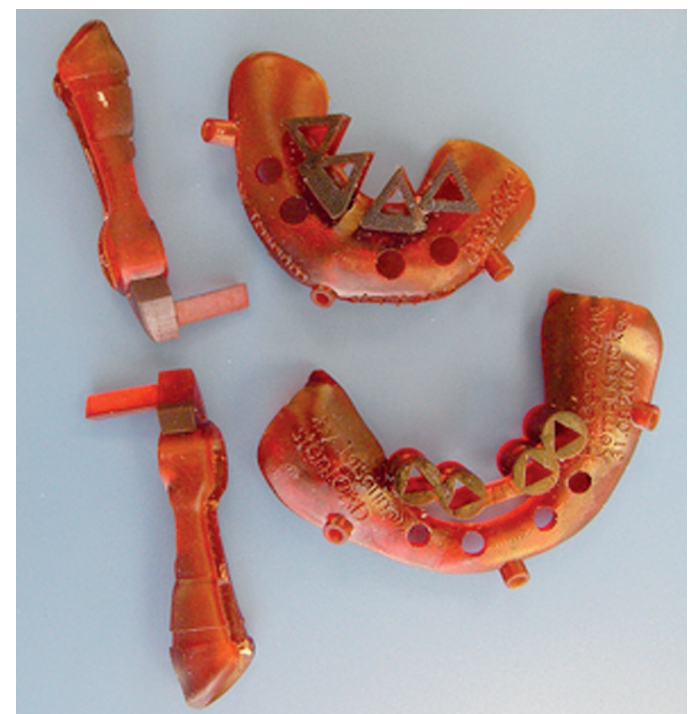

Resim 7. Anguldruva yönlendirmeli rehber kılavuz parçaları

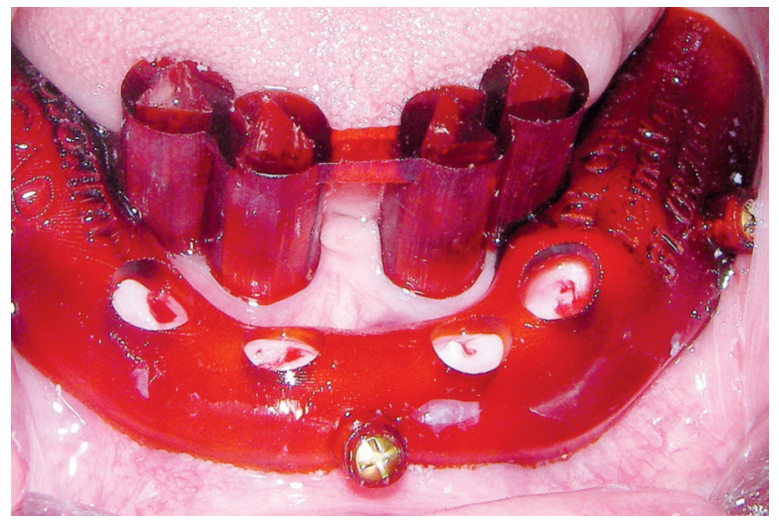

Resim 8. Rehber kılavuzların ağız içerisinde stabilizasyonlarını sağlamak için kullanılan osseosentez vidaları

rindendir. Navigasyon sistemleri genellikle cerrahın elindeki anguldruvaya bağlanan bir sensör sistemiyle hastanın ağzına takılan diğer bir sensör sisteminin uzayda birbirleriyle olan ilişkilerini göstererek doğru konumlandırmayı sağlamaya çalışmaktadır. ${ }^{52}$ Dental implant operasyonlarında 3-boyutlu cerrahi operasyonu gerçekleştirmek için bu tür yöntemler kullanılır. ${ }^{53-55}$ İmplant operasyonu detaylı olarak ekran üzerinde gözlenebilmektedir. Böylece operasyon öncesi yapılan planlama minimum hata ile transfer edilerek operasyon gerçekleştirilir. ${ }^{30,53,55,56}$ Navigasyon yöntemi artan bir şekilde çeşitli oral ve maksillofasiyal cerrahi işlemlerinde kullanılmaktadır. Literatürde in vivo bir çalışma ile karşılaşılmamış olup, çalışmalar genellikle in vitro olarak yapılmıştır. ${ }^{56}$

\section{Cerrahi kılavuzların hassasiyeti}

Stereolitografi yöntemiyle üretilen cerrahi kılavuzların diğer konvansiyonel cerrahi kılavuzlara olan üstünlükleri gösterilmiş ${ }^{48}$ ve SLA cerrahi kılavuzların özellikle anatomik bölgelere yakın komşuluk durumlarında, çoklu implant yerleştirilmesi planlanan durumlarda paralellik sağlamak amacıyla tercih edilmesi gerektiği belirtilmiştir. ${ }^{13,37}$ Bunun yanında literatür incelendiğinde bu tarz kılavuzlarla yapılan operasyonların hassasiyetinin değerlendirildiği görülmekte ve bu kılavuzların planlanan implantların cerrahi alana aktarılmasında başarılı apareyler oldukları belirtilmektedir. ${ }^{49-51}$

Bu kılavuzların hassasiyetinin değerlendirilmesinde çalışmaların hemen hemen hepsi verilerin üst üste çakıştırılması yöntemini kullanmaktadır. ${ }^{56} \mathrm{Bu}$ yöntemde, bilgisayar ortamında planlanan implantlar ile operasyon sonrası yerleştirilen implantların tomografi verileri üst üste çakıştırılmaktadır. Daha sonra, koronal ve apeks bölgesindeki pozisyonel ve ayrıca planlama ile yerleştirilen implant arasındaki açısal sapma tespit edilerek sistemin hassasiyeti istatiksel olarak değerlendirilmektedir (Resim 9). ${ }^{19,22}$

Frez yönlendirici cerrahi kılavuzların hassasiyetinin 21 hastada 94 adet implant yerleştirilerek değerlendirildiği bir çalışmada planlanan implantlar ile operasyon sonrası tomografi verileri karşılaştırılmıştır. ${ }^{9}$ Çalışmanın sonuçları incelendiğinde; $4.9^{\circ} \pm 2.36^{\circ}$ açısal sapma, 1.22 $\pm 0.85 \mathrm{~mm}$ implantın koronal bölgesinde ve $1.51 \pm 1 \mathrm{~mm}$ implantın apeks bölgesinde kayma tespit edilmiştir. Elde edilen verilerin ışığı altında araştırmacılar SLA cerrahi kılavuzların yeterli hassasiyet gösterdiğini belirtmiş ve flepsiz cerrahi uygulamalarının da bu yöntemle yapılabileceği belirtilmiştir. Bunun üzerine aynı grup, diş, kemik ve mukoza destekli frez yönlendirici SLA cerrahi kılavuzları karŞılaştırmıştır. ${ }^{13}$ Ozan ve ark. ${ }^{13} 30$ hastada 110 implant üzerinde yaptıkları bu çalışmada, diş destekli SLA cerrahi kılavuzları istatiksel olarak daha başarılı bulmuşlardır. Çalışmanın sonuçlarını değerlendirdiklerinde, diş destekli kılavuzların daha başarılı çıkmasına karşın mukoza ve kemik destekli kılavuzların da güvenli bir şekilde kullanılabileceğini belirtmişlerdir (Tablo 2).

Ozan ve ark..$^{45}$ yaptıkları diğer bir çalışmada ise 54 hastaya 216 implant yerleştirerek frez yönlendirici ve an-

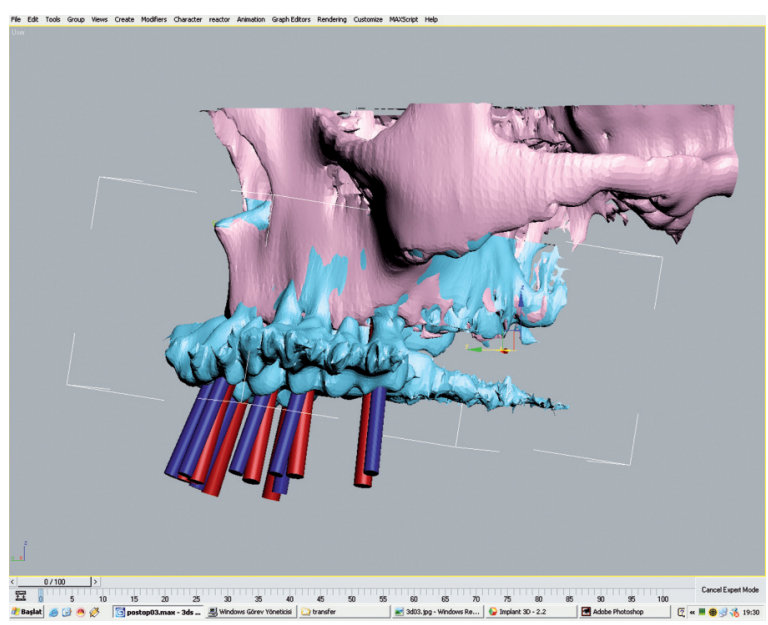

Resim 9. Planlanan ve yerleştirilen implant arasındaki sapmaların çakıştırma yöntemiyle belirlenmesi 
Tablo 2. Rehber kılavuzlar eşliğinde yapılan çalışmalar

\begin{tabular}{|c|c|c|c|c|c|c|}
\hline Araştırma & Kılavuz tipi & Hasta sayısı & İmplant sayısı & $\begin{array}{c}\text { Açısal sapma } \\
\left({ }^{\circ}\right)\end{array}$ & $\begin{array}{c}\text { Boyun bölgesindeki } \\
\text { sapma }(\mathrm{mm})\end{array}$ & $\begin{array}{c}\text { Apeks bölgesindeki } \\
\text { sapma }(\mathrm{mm})\end{array}$ \\
\hline \multirow[t]{3}{*}{ Ersoy ve ark. $(2008)^{9}$} & Diş destekli kılavuz & 21 & 26 & & & \\
\hline & Kemik destekli kılavuz & & 45 & $4.80 \pm 2.10$ & $1.16 \pm 0.76$ & $1.53 \pm 1.06$ \\
\hline & Mukoza destekli kılavuz & & 23 & & & \\
\hline \multirow[t]{3}{*}{ Ozan ve ark. $(2009)^{13}$} & Diş destekli kılavuz & 30 & 30 & $2.91 \pm 1.3$ & $0.87 \pm 0.4$ & $0.95 \pm 0.6$ \\
\hline & Kemik destekli kılavuz & & 50 & $4.63 \pm 2.6$ & $1.28 \pm 0.9$ & $1.57 \pm 0.9$ \\
\hline & Mukoza destekli kılavuz & & 30 & $4.51 \pm 2.1$ & $1.06 \pm 0.6$ & $1.6 \pm 1$ \\
\hline \multirow[t]{2}{*}{ Arısan ve ark. $(2010)^{40}$} & Frez yönlendirmeli & 54 & 132 & $5 \pm 1.66$ & $1.7 \pm 0.52$ & $1.99 \pm 0.64$ \\
\hline & Anguldruva yönlendirmeli & & 147 & $4.73 \pm 1.28$ & $1.56 \pm 0.25$ & $1.86 \pm 0.4$ \\
\hline \multirow[t]{2}{*}{ Ozan ve ark. $(2011)^{45}$} & Frez yönlendirmeli & 54 & 124 & $5.32 \pm 1.96$ & Ç.I. & Ç.İ. \\
\hline & Anguldruva yönlendirmeli & & 92 & $3.73 \pm 1.14$ & & \\
\hline Casap ve ark. $(2004)^{30}$ & Navigasyon yöntemi & 7 çalışma modeli & 21 & Ç.I. & $0.35 \pm 0.14$ & $0.35 \pm 0.14$ \\
\hline Kang ve ark. $(2014)^{56}$ & Navigasyon yöntemi & 10 çalışma modeli & 80 & Ç.ì. & Ç.İ. & 0.52 \\
\hline
\end{tabular}

Ç.ì.: Çalışmada incelenmemiştir.

guldruva yönlendirici SLA cerrahi kılavuzların hassasiyetini karşılaştırmışlardır. Çalışmada, 124 implant frez yönlendirmeli rehber kılavuz eşliğinde yerleştirilirken, 92 implant anguldruva yönlendirici cerrahi kılavuz kullanılarak yerleştirilmiştir. Sonuçlar incelendiğinde anguldruva yönlendirici cerrahi kılavuzlar istatiksel olarak daha başarılı bulunmuştur. ${ }^{45}$ Benzer bir çalışmada anguldruva yönlendirici kılavuzların daha hassas sonuçlar verdiği vurgulanmıştır ve anguldruva yönlendirmeli kılavuzun, frez yönlendirmeli cerrahi kılavuz ile karşılaştırıldığında daha başarılı olarak nitelendirilebileceği belirtilmiştir. ${ }^{40}$ (Tablo 2 ).

Casap ve ark. ${ }^{30}$ özel seramik çene modellerinde yapmış olduğu in vitro çalışmada, 7 farklı çene modeline toplamda 21 adet implant yerleştirmiştir. İşlem öncesi ve sonrası çekilen tomografi verileri çakıştırıldığında açısal sapmada istatiksel olarak anlamlı bir fark saptamazlarken; konumsal olarak ortalama $0.35 \pm 0.14$ $\mathrm{mm}$ sapma rapor edilmiştir. Elde edilen veriler değerlendirildiğinde sistem in vitro olarak başarılı bulunurken, yöntemin klinik çalışmalarla desteklenmesi gerekliliği vurgulanmıştır (Tablo 2).

\section{SonUC}

Üç-boyutlu KIBT/BT destekli bilgisayar simulasyonları kullanılarak hazırlanan cerrahi kılavuzlarla yapılan tedavinin estetik ve fonksiyonel olarak başarılı olduğuna dair literatürde çok sayıda kanıt bulunmaktadır. Bu nedenle, bu tarz uygulamaların güvenle kullanabilecekleri hakkında yeterli yargıya varılabilmektedir.

Çıkar çatışması: Yazarlar bu çalışmayla ilgili herhangi bir çıkar çatışmalarının bulunmadığını bildirmişlerdir.

\section{KAYNAKLAR}

1. Misch CE. Contemporary implant dentistry, Tokyo: Mosby Elsevier; 1999. p.56-60.

2. Terzioğlu H, Akkaya M, Ozan O. The use of a computerized tomographybased software program with a flapless surgical technique in implant dentistry: a case report. Int J Oral Maxillofac Implants 2008;24:137-42.
3. Dhingra K. Oral rehabilitation considerations for partially edentulous periodontal patients. J Prosthodont 2012;21:494-513.

4. Esposito M, Grusovin MG, Chew YS, Coulthard P, Worthington HV. Interventions for replacing missing teeth: 1- versus 2-stage implant placement. Cochrane Database Syst Rev 2009;3:CD006698.

5. Avila G, Galindo-Moreno P, Soehren S, Misch CE, Morelli T, Wang $\mathrm{HL}$. A novel decision-making process for tooth retention or extraction. J Periodontol 2009;80:476-91.

6. Hobo S, Ichida E, Garcia LT. Osseointegration and occlusal rehabilitation, Osaka: Quintessence; 1996. p.56-62.

7. Ganz SD. Techniques for the use of CT imaging for the fabrication of surgical guides. Atlas Oral Maxillofac Surg Clin North Am 2006;14:75-97.

8. Akova T, Üstün Y. Implant tedavisinde bilgisayarlı tomografi destekli cerrahi kılavuzların kullanımı. Atatürk Üniversitesi Diş Hekimliği Fakültesi Dergisi 2006;16:16-21.

9. Ersoy AE, Turkyilmaz I, Ozan O, McGlumphy EA. Reliability of implant placement with stereolithographic surgical guides generated from computed tomography: clinical data from 94 implants. J Periodontol 2008;79:1339-45.

10. Ozan O, Yilmaz B, Pekperdahci T. The prosthodontic rehabilitation of malpositioned implants in a patient with basal cell carcinoma: a clinical report. J Prosthet Dent 2008;99:174-7.

11. Block MS, Cervini D, Chang A, Gottsegen GB. Anterior maxillary advancement using tooth-supported distraction osteogenesis. J Oral Maxillofac Surg 1995;53:561-5.

12. Xiaojun C, Yanping L, Yiqun W, Changtoo W. Computer-aided oral implantology: methods and applications. J Med Eng Technol 2007;31:45967.

13. Ozan O, Turkyilmaz I, Ersoy AE, McGlumphy EA, Rosenstiel SF. Clinical accuracy of 3 different types of computed tomography-derived stereolithographic surgical guides in implant placement. J Oral Maxillofac Surg 2009;67:394-401.

14. Reiskin $A B$. Implant planning. Status, controversies, and new developments. Dent Clin North Am 1998;42:47-56.

15. Amorfini L, Storelli S, Romeo E. Rehabilitation of a dentate mandible requiring a full arch rehabilitation. Immediate loading of a fixed complete denture on 8 implants placed with a bone-supported surgical computerplanned guide: a case report. J Oral Implantol 2011;37 Spec No:106-13.

16. Bankoglu M, Karakoca-Nemli S. Intraoral implant planlamasında üç boyutlu görüntüleme tekniklerinin kullanımı. Ankara Diş Hekimleri Odası Klinik Bilimler Dergisi 2010;4:33-42.

17. Pjetursson BE, Zwahlen M, Lang NP. Quality of reporting of clinical studies to assess and compare performance of implant-supported restorations. J Clin Periodontol 2012;39:139-59.

18. Eltas A, Dündar DS, Uzun İH, Malkoç MA. Dental implant başarısının ve hasta profilinin değerlendirilmesi: Retrospektif bir çalışma. Atatürk Üniversitesi Diş Hekimliği Fakültesi Dergisi 2013;21:1-8.

19. Ozan O, Seker E, Kurtulmus-Yilmaz S, Ersoy AE. Clinical application of stereolithographic surgical guide with a handpiece guidance apparatus: a case report. J Oral Implantol 2012;38:603-9. 
20. BouSerhal C, Jacobs R, Quirynen M, van Steenberghe D. Imaging technique selection for the preoperative planning of oral implants: a review of the literature. Clin Implant Dent Relat Res 2002;4:156-72.

21. Chan HL, Misch K, Wang HL. Dental imaging in implant treatment planning. Implant Dent 2010;19:288-98.

22. Ozan O, Orhan K, Aksoy S, Icen M, Bilecenoglu B, Sakul BU. The effect of removable partial dentures on alveolar bone resorption: a retrospective study with cone-beam computed tomography. J Prosthodont 2013;22:42-8.

23. Ganz SD. Presurgical planning with CT-derived fabrication of surgical guides. J Oral Maxillofac Surg 2005;63:59-71.

24. Widmann G, Bale RJ. Accuracy in computer-aided implant surgery-a review. Int J Oral Maxillofac Implants 2005;21:305-13.

25. Spector L. Computer-aided dental implant planning. Dent Clin North Am 2008;52:761-75.

26. Dandekeri SS, Sowmya MK, Bhandary S. Stereolithographic surgical template: a review. J Clin Diagn Res 2013;7:2093-5.

27. Turkyilmaz I, Ozan O, Yilmaz B, Ersoy AE. Determination of bone quality of 372 implant recipient sites using hounsfield unit from computerized tomography: a clinical study. Clin Implant Dent Relat Res 2008;10:238-44.

28. Sertgöz A. İmplantolojide 3 boyutlu planlama ve güvenli implant yerleştirmesi. İstanbul Dişhekimleri Odası Dergisi 2012;143:44-7.

29. Garber DA, Belser UC. Restoration-driven implant placement with restoration-generated site development. Compend Contin Educ Dent 1995;16:796,798-802,804.

30. Casap N, Wexler A, Persky N, Schneider A, Lustmann J. Navigation surgery for dental implants: assessment of accuracy of the image guided implantology system. J Oral Maxillofac Surg 2004;62:116-9.

31. Kau CH, Bozic M, English J, Lee R, Bussa H, Ellis RK. Cone- beam computed tomography of the maxillofacial region--an update. Int $\mathrm{J}$ Med Robot 2009;5:366-80.

32. Scarfe WC, Farman AG, Sukovic P. Clinical applications of conebeam computed tomography in dental practice. J Can Dent Assoc 2006;72:75-80

33. White SC, Pharoah MJ. Oral radiology principles and interpretation, Los Angeles, CA: Mosby Elsevier; 2009. p.110-4.

34. Lofthag-Hansen S, Gröndahl K, Ekestubbe A. Cone-beam CT for preoperative implant planning in posterior mandible: visibility of anatomic landmarks. Clin Implant Dent Relat Res 2009;11:246-55.

35. De Vos J, Casselman GR, Swennen J. Cone-beam computerized tomography $(\mathrm{CBCT})$ imaging of the oral and maxillofacial region: a systematic review of the literature. Int J Oral Maxillofac Surg 2009;38:60925.

36. Jabero M, Sarment DP. Advanced surgical guidance technology: a review. Implant Dent 2006;15:135-42.

37. Ozan O, Pekperdahci T, Kocyigit D, Meric G. Üç boyutlu implant planlaması ve yeni geliştirilmiş bir cerrahi stentle implantların yerleştirilmesi. Turkiye Klinikleri J Dental Sci 2015;21:151-5.

38. Kramer FJ, Baethge C, Swennen G, Rosalh S. Navigated vs. conventional implant insertion for maxillary single tooth replacement. Clin Oral Implants Res 2005;16:60-8.

39. Arisan V, Karabuda CZ, Ozdemir T. Implant surgery using boneand mucosa-supported stereolithographic guides in totally edentulous jaws: surgical and post-operative outcomes of computer-aided vs. standard techniques. Clin Oral Implants Res 2010;21:980-8.

40. Arisan V, Karabuda ZC, Ozdemir T. Accuracy of two stereolithographic guide systems for computer-aided implant placement: a computed tomography-based clinical comparative study. J Periodontol 2010;81:43-51.

41. Sammartino G, Della Valle A, Marenzi G, Gerbino S, Martorelli M, di Lauro $A E$, et al. Stereolithography in oral implantology: a comparison of surgical guides. Implant Dent 2004;13:133-9.

42. Beretta M, Poli PP, Maiorana C. Accuracy of computer-aided template-guided oral implant placement: a prospective clinical study. J Periodontal Implant Sci 2014;44:184-93.

43. Orentlicher G, Abboud M. Guided surgery for implant therapy. Oral Maxillofac Surg Clin North Am 2011;23:239-56.

44. Lal K, White GS, Morea DN, Wright RF. Use of stereolithographic templates for surgical and prosthodontic implant planning and placement. Part I. The concept. J Prosthodont 2006;15:51-8.
45. Ozan O, Orhan K, Turkyilmaz I. Correlation between bone density and angular deviation of implants placed using CT-generated surgical guides. J Craniofac Surg 2011;22:1755-61.

46. Lozada JL, Garbacea A, Goodacre CJ, Kattadiyil MT. Use of a digitally planned and fabricated mandibular complete denture for easy convension to an immediately loaded provisional fixed complete denture. Part 1. Planning and surgical phase. Int J Prosthodont 2014;27:417-21. 47. Misir AF, Sumer M, Yenisey M, Ergioglu E. Effect of surgical drill guide on heat generated from implant drilling. J Oral Maxillofac Surg 2009;67:2663-8.

48. Shapurian T, Damoulis PD, Reiser GM, Griffin TJ, Rand WM. Quantitative evaluation of bone density using the Hounsfield index. Int J Oral Maxillofac Implants 2006;21:290-7.

49. D'Haese J, Vervaeke S, Verbanck N, De Bruyn H. Clinical and radiographic outcome of implants placed using stereolithographic guided surgery: a prospective monocenter study. Int J Oral Maxillofac Implants 2013;28:205-15

50. D'Souza KM, Aras MA. Types of implant surgical guides in dentistry: a review. J Oral Implantol 2012;38:643-52.

51. Valente F, Schiroli G, Sbrenna A. Accuracy of computer-aided ora implant surgery: a clinical and radiographic study. Int J Oral Maxillofac Implants 2009;24:234-42.

52. Alnıaçık G, İnan Ö, Tak Ö. İmplant diş hekimliğinde kullanılan radyografik tekniklerin cerrahi ve protetik tedavideki yararları. Atatürk Üniversitesi Diş Hekimliği Fakültesi Dergisi 2014;8:141-51.

53. Petterson A, Kero T, Gillot L, Cannas B, Fäldt J, Söderberg R, et al. Accuracy of CAD/CAM-guided surgical template implant surgery on human cadavers: Part 1. J Prosthet Dent 2010;103:334-42.

54. Rossi R, Morales RS, Frascaria M, Benzi R, Squadrito N. Planning implants in the esthetic zone using a new implant 3D navigation system. Eur J Esthet Dent 2010;5:172-88.

55. Casap N, Nadel S, Tarazi E, Weiss El. Evaluation of navigation system for dental implantation as a tool to train novice dental practioners. J Oral Maxillofac Surg 2011;69:2548-56

56. Kang SH, Lee JW, Lim SH, Kim YH, Kim MK. Verification of the usability of a navigation method in dental implant surgery: in vitro comparison with the stereolithographic surgical guide template method. J Craniomaxillofac Surg 2014;42:1530-5.

\section{3-dimensional implant planning in prosthetic dentistry and surgical guides}

\section{Abstract}

In implant dentistry, technological inventions are now being utilized in order to achieve better treatment results; thus failures associated with conventional surgical techniques are reduced. With the use of 3-dimensional computer-assisted planning, the density and the width of bone, and anatomic landmarks can be observed in detail and also a 3-dimensional model of the bone tissue can be constructed. By using contemporary radiological and surgical guides, fabrication of implant-supported restorations with superior quality is possible. In this review, information regarding planning methods to get better prosthetic results in dental implant treatments have been given. Also, the accuracy of these methods have been evaluated in the light of the current dental literature.

KEYWORDS: Dental implant; prosthodontics; surgery, computer-assisted 